\title{
Development of pull and push-pull systems for management of lesser mealworm, Alphitobius diaperinus, in poultry houses using alarm and aggregation pheromones
}

\author{
Marla J Hassemer, ${ }^{\mathrm{a}, \mathrm{b}}$ Miguel Borges, ${ }^{\mathrm{b}}$ David M Withall, ${ }^{\mathrm{c}}$ John A Pickett, ${ }^{\mathrm{d}}$ \\ Raul A Laumann, ${ }^{b}$ Michael A Birkett ${ }^{\mathfrak{c}} \odot$ and Maria C Blassioli-Moraes ${ }^{b^{*}} \odot$
}

\begin{abstract}
BACKGROUND: The lesser mealworm, Alphitobius diaperinus (Coleoptera: Tenebrionidae), is the most important insect pest affecting poultry production around the world, with all life stages being susceptible to infection by bacteria, viruses and fungi. Control of $A$. diaperinus in poultry houses using intensive insecticide application is not effective due to the cryptic behaviour of this pest. Here, we evaluated the potential of recently identified $A$. diaperinus alarm (1,4-benzoquinone, 2-methyl-1,4-benzoquinone and 2-ethyl-1,4-benzoquinone) and aggregation [(R)-limonene, 2-nonanone, (E)-ocimene, $(S)$-linalool, $(R)$-daucene and $(E, E)$ - $\alpha$-farnesene] pheromones as tools for the management of this pest in poultry houses in Brazil.
\end{abstract}

RESULTS: Laboratory arena assays with synthetic alarm pheromone confirmed A. diaperinus repellency. In an initial field assay, traps baited with synthetic aggregation pheromone captured significantly more insects than control traps. In further field assays that compared a pull (aggregation pheromone) and a push-pull (simultaneous alarm/aggregation pheromone deployment) system, a higher number of $A$. diaperinus were captured in aggregation pheromone-baited traps in the push-pull system.

CONCLUSION: Our results suggest that alarm and aggregation pheromones can be deployed in poultry houses to trap significant numbers of adult $A$. diaperinus. Studies are underway to determine the potential for using these components as part of an integrated $A$. diaperinus management strategy.

(C) 2018 Society of Chemical Industry

Supporting information may be found in the online version of this article.

Keywords: poultry production; aggregation pheromone; pheromone traps; attractant and repellent

\section{INTRODUCTION}

The lesser mealworm, Alphitobius diaperinus Panzer 1797 (Coleoptera: Tenebrionidae), is the most important insect pest affecting poultry production around the world. ${ }^{1-3}$ Modern broiler facilities offer suitable environmental conditions for $A$. diaperinus proliferation, including high temperatures, dark and sheltered sites, moisture and food availability. As a consequence, poultry houses contain high densities of larvae and adults that aggregate predominantly under feeders and along house edges. ${ }^{4-6}$ In addition, all $A$. diaperinus life stages are susceptible to infection by bacteria, viruses and fungi, characterizing these insects as poultry pathogen vectors. ${ }^{7-10}$ Control of $A$. diaperinus in poultry houses is currently undertaken using intensive insecticide application, causing potential contamination of poultry and aviaries, and threatening the delivery of safe food. ${ }^{11}$ Additionally, due to the cryptic behaviour of this pest, insecticide control is usually not effective. ${ }^{12,13}$ In recent years, several alternative methods for lesser mealworm control have been proposed, with the aim of minimizing the use of insecticides and enhancing the quality of the food that is being produced. ${ }^{14-16}$ Semiochemicals, mainly pheromones, have been suggested for use in monitoring and controlling $A$. diaperinus in poultry houses. ${ }^{17-21}$ Recently, we identified three benzoquinones, i.e. 1,4-benzoquinone, 2-methyl-1,4-benzoquinone and 2-ethyl-1,4-benzoquinone, as alarm pheromone components from the abdominal glands of

\footnotetext{
* Correspondence to: MC Blassioli-Moraes, Semiochemicals Laboratory, Embrapa Genetics Resources and Biotechnology, Parque Estação Biológica, PqEB, Avenue W5 Norte (final), Caixa Postal 02372 - Brasilia, DF - CEP 70770-917, Brazil.E-mail: carolina.blassioli@embrapa.br

a Department of Zoology, Institute of Biological Sciences, University of Brasília, Brasília, Brazil

b Semiochemicals Laboratory, Embrapa Genetics Resources and Biotechnology, Embrapa Genetics Resources and Biotechnology, Brasília, Brazil

c Rothamsted Research, Harpenden, UK

d School of Chemistry, Cardif University, Cardif CF10 3AT, UK
} 
Brazilian male and female $A$. diaperinus. ${ }^{20}$ Furthermore, we also recently identified a male-produced aggregation pheromone for Brazilian A. diaperinus as a six-component blend comprising $(R)$-limonene, 2-nonanone, $(E)$-ocimene, $(S)$-linalool, $(R)$-daucene and $(E, E)-\alpha$-farnesene. ${ }^{21}$ Identification of a six-component blend was a surprising discovery, because earlier work had shown that the aggregation pheromone for North American A. diaperinus comprised only five of these six compounds, with $(E, E)-\alpha$-farnesene being absent from the pheromone blend. ${ }^{17}$ Moreover, we reported that all six pheromone components were needed for attraction of Brazilian A. diaperinus, whereas for the North American population, only three of the components, $(E)$-ocimene, 2-nonanone and $(R)$-daucene, were needed to attract both sexes. ${ }^{19}$

Semiochemicals have great versatility and potential to be used in insect pest management. They can be applied, for example, in push-pull systems combining attractant and repellent semiochemicals, to manipulate the distribution and abundance of pests. $^{22,23}$ The aim of this study was to evaluate the potential of aggregation and alarm pheromones produced by Brazilian A. diaperinus as tools for management of this pest in poultry houses in tropical and subtropical environments. Two different approaches were evaluated: (i) a pull system using a semiochemical blend to attract insects to traps, i.e. traps baited with the synthetic aggregation pheromone (mass-trapping); and (ii) a push-pull system using two semiochemical blends simultaneously, i.e. the synthetic alarm pheromone and traps baited with the synthetic aggregation pheromone, with the alarm pheromone being deployed to displace insects from their hiding spots and the aggregation pheromone-baited traps to attract displaced insects into traps. In addition, the pheromone traps were evaluated in poultry houses with different population levels, i.e. with new (low population level) and used (high population level) poultry litter. Experiments were conducted in two different locations, in the centre-west (tropical, with temperatures of 25 to $35^{\circ} \mathrm{C}$ ) and south (sub-tropical, with temperatures of 5 to $25^{\circ} \mathrm{C}$ of Brazil), to evaluate whether different weather temperatures could interfere with insect capture. These areas were chosen because of their importance to the Brazilian poultry industry.

\section{MATERIAL AND METHODS}

\subsection{Chemicals}

Hexane (HPLC grade, $\geq 97 \%$ ) and diethyl ether were purchased from Sigma-Aldrich (Steinheim, Germany) and re-distilled before use. 1,4-Benzoquinone (98\%) and 2-methyl-1,4-benzoquinone (98\%) were also purchased from Sigma-Aldrich. (R)-Limonene (95\%) was purchased from TCl-America (Portland, OR, USA). 2-Nonanone (99\%) was provided by Jeffrey R. Aldrich Consulting LLC (Santa Cruz, CA, USA). 2-Ethyl-1,4-benzoquinone (98\%), $(E)$-ocimene (98\%), (S)-linalool (98\%), (R)-daucene (87\%) and $(E, E)-\alpha$-farnesene $(>95 \%)$ were synthesized in the laboratory as described previously. ${ }^{20,21}$

\subsection{Laboratory experiments - alarm pheromone}

To evaluate the potential of the $A$. diaperinus alarm pheromone as the push component of a push - pull system, laboratory arena tests were conducted. Because of the cryptic behaviour of $A$. diaperinus, the bioassay was conducted under photophase conditions for $24 \mathrm{~h}$ to force insects to find hiding places. The arena consisted of open plastic boxes $(40 \times 60 \times 10 \mathrm{~cm})$, in which two polyvinyl chloride (PVC) tubes $(3 \mathrm{~cm}$ diameter $\times$ and $20 \mathrm{~cm}$ length) were placed close to the horizontal edges of the arena. Two treatments were evaluated: (i) the alarm pheromone, which consisted of a solution of 1,4-benzoquinone ( $1 \mu \mathrm{g}), 2$-methyl-1,4-benzoquinone $(249 \mu \mathrm{g})$ and 2-ethyl-1,4-benzoquinone $(750 \mu \mathrm{g})$ in hexane $(400 \mu \mathrm{L})$; and (ii) a solvent control, which consisted of hexane $(400 \mu \mathrm{L})$. Treatments were placed on folded pieces of filter paper $\left(5 \times 2 \mathrm{~cm}, 80 \mathrm{~g} \mathrm{~m}^{-2}\right.$, J. Prolab, PR-Brazil), which were placed into the PVC tubes. Filter papers were replaced every $24 \mathrm{~h}$. The following experiments were conducted: (i) both PVC tubes treated with hexane (negative control), (ii) one PVC tube treated with solvent and the other treated with alarm pheromone, and (iii) both PVC tubes treated with alarm pheromone (positive control). For each experiment, 100 insects (50 males and 50 females) were released at the centre of arena. After $24 \mathrm{~h}$, the numbers of insects inside the PVC tubes and in the centre of the arena were counted. Each experiment was replicated 10 times.

\subsection{Pitfall traps}

Pitfall traps designed and used in field experiments comprised cylindrical plastic boxes $(10 \mathrm{~cm}$ height $\times 14 \mathrm{~cm}$ diameter). For each trap, a $6-\mathrm{cm}$ diameter hole was drilled into the lid, through which a rubber septum impregnated with synthetic aggregation pheromone could be placed inside the trap environment. Each septum was suspended by a wire that was attached to a round cardboard cover, which was attached to the plastic lid using screws (Fig. 1). The cardboard was attached such that a 2-cm gap between it and the lid of the plastic box could be maintained, sufficient to allow insects to move into the trap. Each trap was buried in poultry litter up to the level of the lid, taking care not to cover the lid completely, leaving space for the pheromonal plume to disperse above and through the poultry litter. Prior to their use in in poultry houses, traps were tested in the laboratory to determine whether insects would be able to escape after falling into them. For this, 1000 insects were placed inside a trap buried in a plastic box $(20 \times 40 \mathrm{~cm})$ containing wood shavings $(n=10)$. After $24 \mathrm{~h}$, the insects were counted and none had escaped.

\subsection{Pheromone lures}

Rubber septa (10 mm, Sigma-Aldrich) were cleaned by Soxhlet extraction $(\times 2)$ with hexane for $4 \mathrm{~h}$, followed by drying at $40^{\circ} \mathrm{C}$ overnight in a gravity convection oven (Precision, Chicago, IL, USA). If working with a greater number of septa or larger septa, it is preferable to remove the excess of hexane in a fume hood rather than by heating, for safety reasons. For formulation of the synthetic aggregation pheromone, the six pheromone components were added to one rubber septum in the same ratio produced by males, with the total combined amount of the six compounds being $1 \mathrm{mg} .{ }^{17}$ A solution with $(R)$-limonene $230 \mu \mathrm{g}$, $(E)$-ocimene $160 \mu \mathrm{g}$, 2-nonanone $40 \mu \mathrm{g}$, (S)-linalool $260 \mu \mathrm{g}$, $(R)$-daucene $80 \mu \mathrm{g}$ and $(E, E)-\alpha$-farnesene $230 \mu \mathrm{g}$ in hexane $(200 \mu \mathrm{L})$ was prepared and used. The alarm pheromone was formulated in the same proportions produced by $A$. diaperinus in their abdominal glands, ${ }^{20}$ i.e. $1 \mu \mathrm{g}$ 1,4-benzoquinone, $249 \mu \mathrm{g}$ 2-methyl-1,4-benzoquinone and $750 \mu \mathrm{g}$ 2-ethyl-1,4-benzoquinone were diluted in diethyl ether $(200 \mu \mathrm{L})$ and added to a septum. After septa were impregnated with either aggregation or alarm pheromone components, they were left in a laminar flow hood at room temperature to allow solvent evaporation for $8 \mathrm{~h}$. Pheromone-baited septa were then stored in a sealed aluminium storage bags (Mitsubishi Gas Chemicals Co., Inc., Tokyo, Japan) at $-20^{\circ} \mathrm{C}$ until required for use in release rate experiments. 


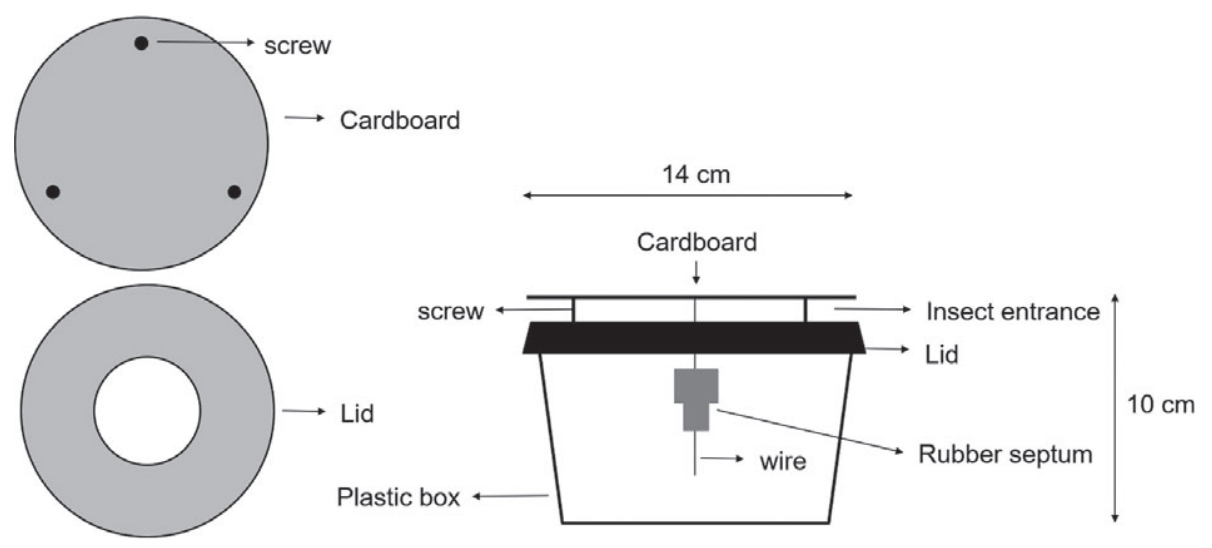

Figure 1. Schematic drawing of pitfall trap.

\subsection{Pheromone release rate}

To verify the volatile emission ratio from rubber septa impregnated with aggregation pheromone $(N=4)$ and alarm pheromone $(N=4)$ components, each septum was placed individually into a glass syringe $(30 \mathrm{~mL})$. One end of the syringe was connected to an activated charcoal filter (4-20 mesh) and the other end was connected to a glass tube containing the adsorbent Tenax GR (100 mg, Restek Corporation, Bellefonte, PA, USA). The tube containing the adsorbent was connected to a vacuum pump and purified air was drawn through the tube at $300 \mathrm{~mL} \mathrm{~min}^{-1}$. The volatiles were collected every $24 \mathrm{~h}$ for 3 consecutive days. The trapped volatiles were eluted from the adsorbent with hexane $(1 \mathrm{~mL})$, and an internal standard ( $1 \mu \mathrm{L}$ of $1 \mathrm{mg} \mathrm{mL}^{-1}(E)$-caryophyllene) was added to the sample. After addition of the IS, the samples were concentrated under a gentle flow of nitrogen to a final volume of $50 \mu \mathrm{L}$. The concentrated extracts were kept at $-20^{\circ} \mathrm{C}$ until required for chemical analysis.

\subsection{Chemical analyses}

Gas chromatography (GC) analyses of volatile extracts collected from impregnated septa were performed using a gas chromatograph (Agilent 7890A) equipped with a DB-5MS column $(30 \mathrm{~m}$ length, $0.25 \mathrm{~mm}$ i.d., $0.25 \mu \mathrm{m}$ film thickness; Supelco, Bellefonte, PA, USA) and a split-splitless injector. The carrier gas was helium. The oven temperature programme started at $50^{\circ} \mathrm{C}$ for $2 \mathrm{~min}$, increased at a rate of $15^{\circ} \mathrm{C} \mathrm{min}-1$ to $250^{\circ} \mathrm{C}$, with a final hold time of $20 \mathrm{~min}$. The column effluent was analysed using a flame ionization detector (FID) at $270^{\circ} \mathrm{C}$. One microlitre of each selected sample was injected in splitless mode; the injector temperature was $250^{\circ} \mathrm{C}$. Compounds were quantified by comparing GC peak areas with the peak area of the internal standard, $(E)$-caryophyllene, prepared at a final concentration of $20 \mu \mathrm{g} \mathrm{mL}^{-1}$. $^{20}$

\subsection{Aggregation pheromone field tests}

Field experiments with $A$. diaperinus aggregation pheromone were performed in commercial poultry farms in Brasília, Distrito Federal $\left(15^{\circ} 59^{\prime} 40.6^{\prime \prime} \mathrm{S}, 47^{\circ} 37^{\prime} 23.4^{\prime \prime} \mathrm{W}\right)$ and Concórdia, Santa Catarina $\left(27^{\circ} 18^{\prime} 36.2^{\prime \prime} \mathrm{S}, 51^{\circ} 59^{\prime} 53.1^{\prime \prime} \mathrm{W}\right)$, Brazil. The poultry houses used in the current study were $120 \mathrm{~m}$ long, $10 \mathrm{~m}$ wide and $3 \mathrm{~m}$ high. The houses were an open-sided design, with $35-\mathrm{cm}$ high sidewalls closed by a wire screen $(7 \mathrm{~cm}$ mesh diameter) up to the roof and covered by a yellow plastic curtain to provide shelter. This design prevented other birds from getting into the poultry houses. The yellow curtain was either opened or closed to keep the internal temperature consistent and provide necessary protection from excessive heat. During the experiments, the curtains remained open. ${ }^{24} \mathrm{~A}$ single replicate consisted of one commercial poultry production building ( $10 \mathrm{~m}$ width $\times 120 \mathrm{~m}$ length) with 20 pitfall traps (Fig. 1) containing the treatments installed every $10 \mathrm{~m}$ in two rows (Fig. 2, pull aviary). The population density of $A$. diaperinus is distributed as strong aggregations in poultry houses, ${ }^{2,4}$ and, therefore, to avoid bias due the uneven population distribution, the experiment had a paired design. Two treatments were tested in the poultry houses: (i) traps containing the aggregation pheromone septa $(N=10)$, and (ii) traps with control (hexane) septa $(N=10)$. To evaluate the infestation level of each building, 20 manual samplings $\left(1000 \mathrm{~cm}^{3}\right)$ of poultry litter were collected between the trap positions (Fig. 2). Samples were transferred to the laboratory, and adults were separated from the litter and counted. The experiments were conducted during the time between flocks, after hens had been moved out. The traps remained in position for $48 \mathrm{~h}$ and were then taken to the laboratory for insect counting. Random samples of 50 beetles from each trap and treatment were dissected to determine the sex ratio. The experiments were conducted under two different conditions: (i) in new poultry litter, where the building was cleaned, and all the litter material was replaced with fresh material before the next chicken flock arrived; and (ii) in used poultry litter, where the poultry material was exposed to two or more chicken flocks. In addition, the experiments were performed under different climate conditions, i.e. in central-west Brazil, Distrito Federal, where the average outdoor temperature during the experimental time (November - February) was $25.80 \pm 3.45^{\circ} \mathrm{C}$ (mean \pm SD) and in Santa Catarina, where the average outdoor temperature during the experimental time (June-August) was $10.27 \pm 1.94{ }^{\circ} \mathrm{C}$. For each poultry litter and location, experiments were repeated 10 times.

\subsection{Pull and push-pull field tests}

The experimental unit consisted of two poultry houses with a similar infestation level (evaluated previously by manual sampling). One building, described as the 'pull' aviary, contained 10 aggregation pheromone traps and 10 control traps as described above (Fig. 2, pull aviary). In the other building, a push-pull system was set up, comprising of 10 aggregation pheromone traps, 10 control traps and 17 alarm pheromone releasers that were distributed as follows: 12 along the edges and five in the centre line next to the central pillars (Fig. 2, push-pull aviary). The releasers were allocated in wire cages ( $5 \mathrm{~cm}$ height $\times 3 \mathrm{~cm}$ diameter) and left above 


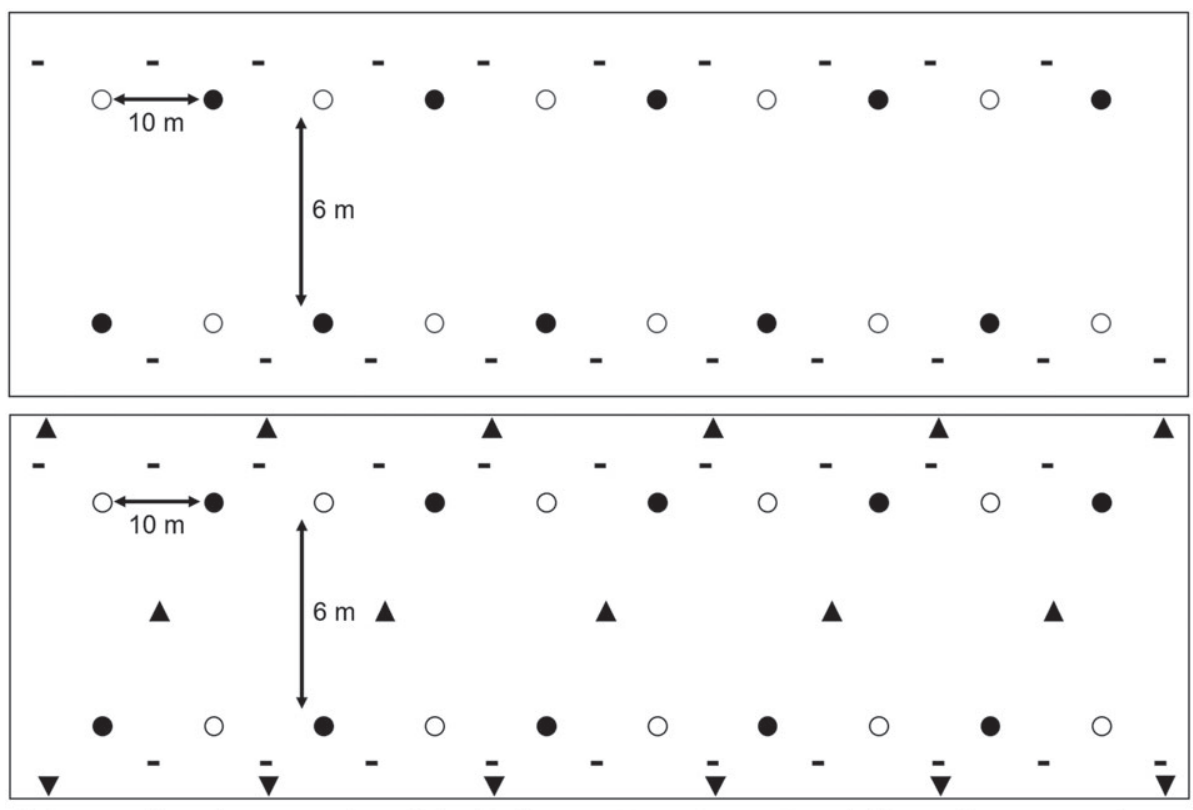

Aggregation pheromone trap $\bigcirc$ Control trap - Manual sampling $\Delta$ Alarm pheromone releaser

Figure 2. Schematic drawing of trap distribution in poultry houses.

the litter. Six replicates were performed per treatment and climate condition. To evaluate the infestation level of each building, 20 manual samplings $\left(1000 \mathrm{~cm}^{3}\right)$ of poultry litter were collected between the trap positions (Fig. 2). The experiments were conducted during the time between flocks, i.e. after the hens had been moved out. Traps remained in position for $24 \mathrm{~h}$, and were then taken to the laboratory for insect counting.

\subsection{Statistical analyses}

The quantity of each pheromone component released from rubber septa during the first 3 days following impregnation was transformed to proportion-released data and analysed by analysis of variance (ANOVA) with repeated measures. Male and female captures in aggregation pheromone traps and control traps were evaluated using a chi-square test. The mean of insects captured in each treatment in the arena test as well as in all field tests were analysed using generalized linear model (GLM) and deviance analyses with Poisson error distribution with logarithm link function and contrast analyses when necessary. All the statistical analyses were conducted using the statistical program R 2.14.0, and significance was accepted at the $\alpha \leq 0.05$ level. $^{25}$

\section{RESULTS}

\subsection{Alarm pheromone - laboratory assays}

In arena assays using synthetic alarm pheromone, when both PVC tubes were treated with solvent control (hexane), significantly more $A$. diaperinus were found in PVC tubes compared with the arena $\left(\chi^{2}=9.19, \mathrm{df}=2, P=0.010\right)$, but there was no difference between PVC tubes (Fig. 3a). When one PVC tube was treated with the alarm pheromone and the other was treated with solvent, significantly fewer $A$. diaperinus were found in the tube treated with the alarm pheromone compared with the solvent-treated PVC tube or arena $\left(\chi^{2}=88.31, \mathrm{df}=2, P<0.001\right)$ (Fig. 3b). Furthermore, when both PVC tubes were treated with the alarm pheromone, a significantly higher number of insects remained outside the PVC tubes $\left(\chi^{2}=311.41, \mathrm{df}=2, P<0.001\right)$ (Fig. 3c).

\subsection{Pheromone release from formulations}

GC analysis of air entrainment extracts collected from aggregation pheromone-impregnated rubber septa showed that all compounds were released, but the mean proportion of components released from septa differed from the proportion initially added to the septa (Table S1). The component $(E, E)$ - $\alpha$-farnesene was released in lower amounts compared with the original ratio loaded. This could occur due to either competition with the other components, the different vapour pressure of the components or the higher affinity of this sesquiterpene with the rubber septa material. Possible degradation of this component was discarded, because when septa were washed with hexane, this component was recovered almost completely (data not shown). For the alarm pheromone, the compound 1,4-benzoquinone was not detected via GC-FID due to the low quantity added. The other two components were detected and released in a similar ratio to that of the original loading ratio (Table S2).

\subsection{Aggregation pheromone field tests}

The field experiments demonstrated an overall significant treatment effect. Traps baited with synthetic aggregation pheromone captured 2.8 times more adult $A$. diaperinus than control traps $\left(\chi^{2}=10.02, \mathrm{df}=1, P=0.001\right)$ (Fig. S1). Traps baited with aggregation pheromone captured more insects under both clean and used poultry litter conditions in tropical (Distrito Federal: new poultry litter, $\chi^{2}=5.881, \mathrm{df}=1, P=0.015,3.9$ times more catches and used poultry litter, $\chi^{2}=6.037, \mathrm{df}=1, P=0.014,2.8$ times more catches) and subtropical environments (Santa Catarina: new poultry litter, $\chi^{2}=3.853, \mathrm{df}=1, P=0.049,3.1$ times more catches and used poultry litter: $\chi^{2}=3.941, \mathrm{df}=1, P=0.047,2.5$ times more catches) (Fig. 4). Furthermore, the behaviour of immature individuals was not affected by the aggregation pheromone (Distrito Federal: new poultry litter, $\chi^{2}=2.789, \mathrm{df}=1, P=0.094$ and used poultry litter, $\chi^{2}=1.280, \mathrm{df}=1, P=0.257$; Santa Catarina: new poultry litter, $\chi^{2}=0.452, \mathrm{df}=1, P=0.501$ and used poultry litter: $\chi^{2}=3.144, \mathrm{df}=1, P=0.080$ ) (Fig. S2). Additionally, 
(a)

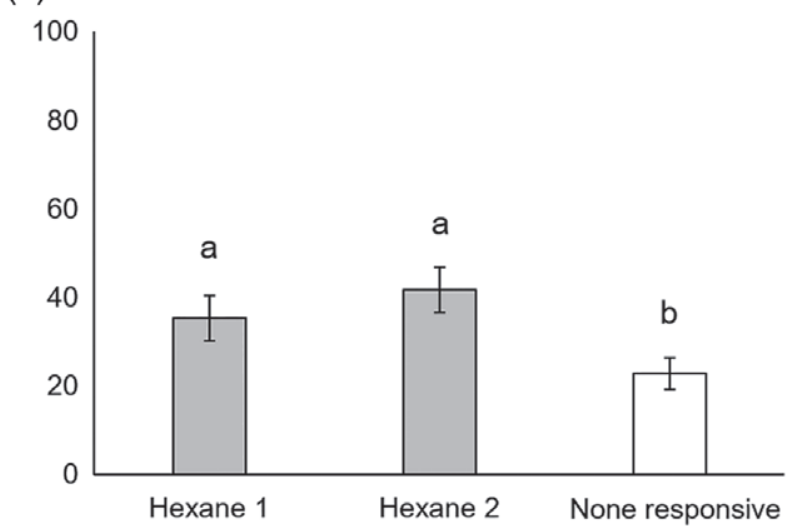

(b)

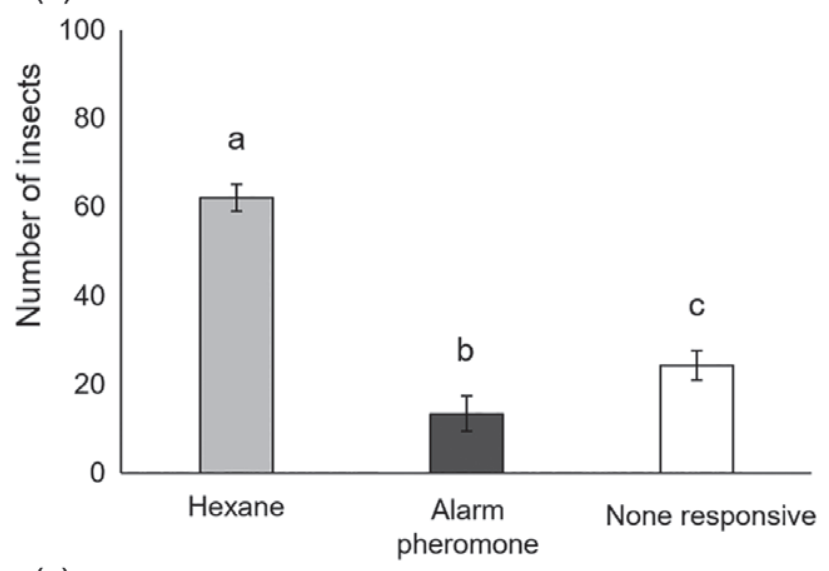

(c)

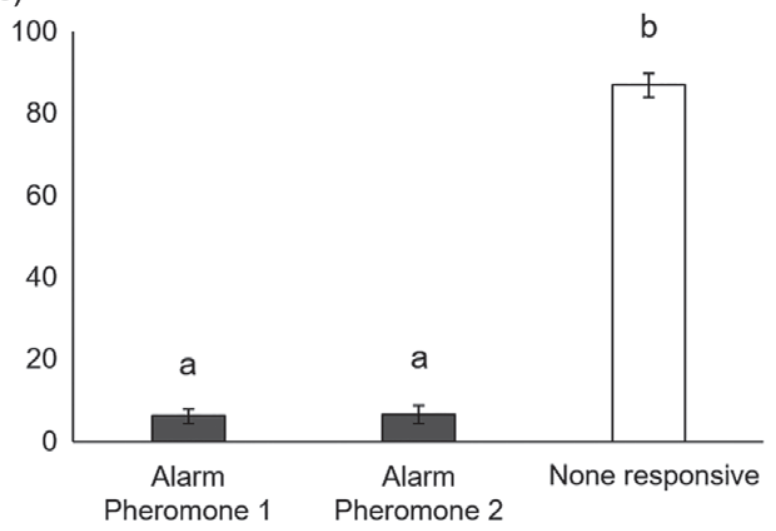

Figure 3. Mean $( \pm \mathrm{SE})$ number of adult Alphitobius diaperinus present in polyvinyl chloride (PVC) tubes and in the arena $24 \mathrm{~h}$ post treatment. (a) Hexane $\times$ hexane, $(b)$ hexane $\times$ alarm pheromone and (c) alarm pheromone $\times$ alarm pheromone. Analyses were carried out using generalized linear model (GLM) and deviance analysis with Poisson error distribution and logarithm link function and contrast analysis. Different letters indicate significant differences within the treatments tested $(\alpha \leq 0.05)$.

there were no differences in the capture of males and females between treatments in new poultry litter (Distrito Federal: control traps, $\chi^{2}=1.28, \mathrm{df}=1, P=0.257$ and pheromone traps, $\chi^{2}=0.72$, $\mathrm{df}=1, P=0.396$; Santa Catarina: control traps, $\chi^{2}=2.88, \mathrm{df}=1$, $P=0.091$ and pheromone traps, $\chi^{2}=2.00, \mathrm{df}=1, P=0.157$ ) and used poultry litter (Distrito Federal: control traps, $\chi^{2}=2.000$, $\mathrm{df}=1, P=0.157$ and pheromone traps, $\chi^{2}=2.88, \mathrm{df}=1, P=0.091$; Santa Catarina: control traps, $\chi^{2}=2.000, \mathrm{df}=1, P=0.157$ and pheromone traps, $\chi^{2}=1.28, \mathrm{df}=1, P=0.257$ ) (Fig. S3).
Distrito Federal

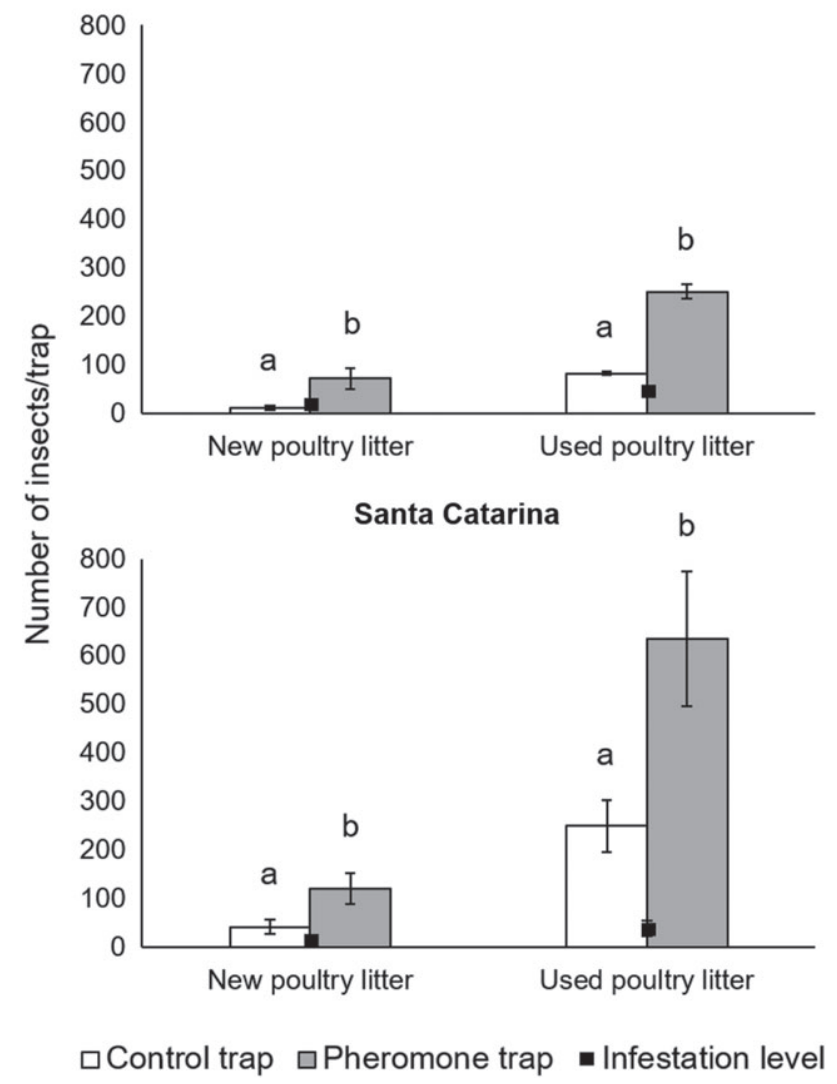

Figure 4. Mean $( \pm \mathrm{SE})$ number of adult Alphitobius diaperinus captured in control and pheromone traps (bars) and infestation level (squares) for each poultry litter (new and used) and location (Distrito Federal and Santa Catarina) (number of adults per $1000 \mathrm{~cm}^{3}$ of litter). Analyses were carried out using generalized linear model (GLM) and deviance analysis with Poisson error distribution and logarithm link function. Different letters in the same type of litter indicate significant differences $(\alpha \leq 0.05)$.

\subsection{Pull and push-pull field experiments}

For these experiments, paired poultry houses with similar levels of $A$. diaperinus infestation were selected for pull and push-pull experiments (Distrito Federal: $\chi^{2}=3.154, \mathrm{df}=1, P=0.076$; Santa Catarina: $\chi^{2}=0.010, \mathrm{df}=1, P=0.917$ ) (Fig. 5). Significantly greater numbers of insects were captured in aggregation pheromone traps, for both pull and push-pull experiments, when compared with control traps (Distrito Federal: pull aviary, $\chi^{2}=55.284$, $\mathrm{df}=1, P<0.001,2.8$ times more catches and push-pull aviary, $\chi^{2}=5.535, \mathrm{df}=1, P=0.018,2.4$ times more catches; Santa Catarina: pull aviary, $\chi^{2}=42.253, \mathrm{df}=1, P<0.001,2.3$ times more catches and push-pull aviary, $\chi^{2}=38.418, \mathrm{df}=1, P<0.001$, 3.1 times more catches). (Fig. 5). Significantly more insects were captured in the push-pull aviary than in the pull aviary (Distrito Federal: control traps, $\chi^{2}=21.646, \mathrm{df}=1, P<0.001,5.2$ times more catches and pheromone traps, $\chi^{2}=32.870, \mathrm{df}=1, P<0.001$, 4.1 times more catches; Santa Catarina: control traps, $\chi^{2}=24.752$, $\mathrm{df}=1, P<0.001,8.1$ times more catches and pheromone traps, $\chi^{2}=34.160, \mathrm{df}=1, P<0.001,9.4$ times more catches) (Fig. 5).

\section{DISCUSSION}

In all field experiments, the number of adult $A$. diaperinus caught in aggregation pheromone-baited traps was higher than in either 
Distrito Federal

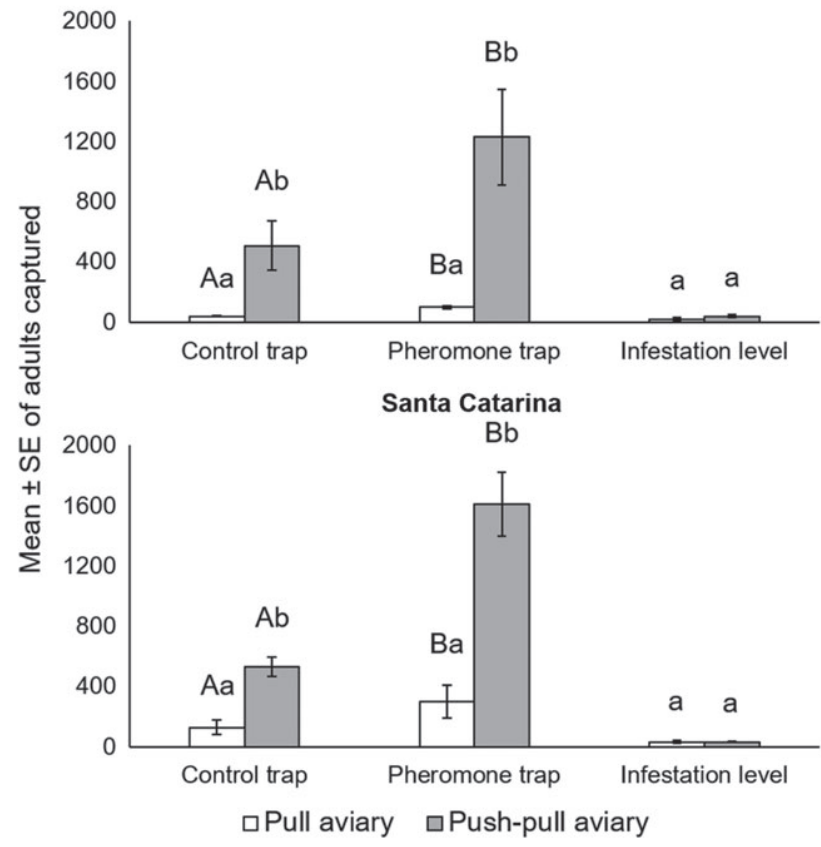

Figure 5. Mean $( \pm \mathrm{SE})$ number of adult Alphitobius diaperinus captured in traps (control and pheromone), and infestation level (number of adults per $1000 \mathrm{~cm}^{3}$ of litter) in a pull and push-pull aviary in Distrito Federal and Santa Catarina. Analyses were carried out using generalized linear model (GLM) and deviance analysis with Poisson error distribution and logarithm link function. Different letters indicate significant differences in the same type of trap between treatments (lowercase) and between control and pheromone traps in the same treatment (uppercase) $(\alpha \leq 0.05)$.

control traps or poultry litter samplings. This indicates the potential for using the aggregation pheromone as a pull component to improve the control of $A$. diaperinus. Although the ratio of aggregation pheromone components emitted from impregnated rubber septa differed from the ratio added, this divergence did not affect attraction to traps, suggesting that the olfactory system of adult $A$. diaperinus possesses plasticity with regard to the relative amounts of the aggregation pheromone components. Future studies will be undertaken to evaluate different ratios between the components in field conditions, to obtain the most efficient formulation.

Pheromones have been used successfully to manage coleopteran pests, including weevils such as the boll weevil, Anthonomus grandis Boheman, the palm weevil, Rhynchophorus palmarum L. and the rice weevil, Sitophilus oryzae L., and tenebrionids including the confused flour beetle, Tribolium confusum du Val and the red flour beetle, Tribolium castaneum Herbst. ${ }^{26-30}$ In our experiments under new poultry litter conditions, a lower number of $A$. diaperinus was, in general, captured compared with experiments under used poultry litter conditions. Used poultry litter provides better conditions for A. diaperinus development and population growth, and when it is replaced, significant numbers of $A$. diaperinus are removed, decreasing the population level in poultry houses. However, replacement of used litter is not sufficient to remove all insects, with some remaining either hidden at the edges or buried in the soil. In our study, we confirmed that, although new poultry litter contains fewer insects than used poultry litter, pheromone-baited traps still capture a significant number of insects. In addition, the higher number of insects captured in the push-pull experiment compared with the pull experiment supports the hypothesis that insects remain hidden in the facilities in the pull experiment. In the push-pull experiment, the alarm pheromone disturbs the insects from their hiding places, favouring higher capture in the aggregation pheromone traps. Brazilian poultry production is located in both tropical and subtropical regions, with $70 \%$ of Brazilian poultry production being concentrated in the south of the country where low temperatures can be reached during winter. ${ }^{31}$ Our results in tropical and subtropical environments shows that attraction of $A$. diaperinus does not appear to be influenced by temperature and other climatic conditions.

Studies on the aggregation pheromone from a US population of $A$. diaperinus comprising five components, i.e. $(R)$-limonene, $(E)$-ocimene, 2-nonanone, $(S)$-linalool and $(R)$-daucene, reported that $(R)$-limonene and $(S)$-linalool were not necessary for attraction, ${ }^{18,19}$ and that higher numbers of larvae were caught in aggregation pheromone-baited traps. ${ }^{18}$ By contrast, Brazilian populations of $A$. diaperinus require all six compounds $[(R)$-limonene, $(E)$-ocimene, 2-nonanone, $(S)$-linalool, $(R)$-daucene and $(E, E)-\alpha$-farnesene] for effective attraction, ${ }^{21}$ and in this study, our data showed that immature stages of $A$. diaperinus were not caught in baited traps. The capture of immature forms of holometabolan species in pheromone traps has been described for other insects, such as T. castaneum, Leptinotarsa decemlineata Say (Coleoptera: Chrysomelidae) and the codling moth, Cydia pomonella L. (Lepidoptera: Tortricidae). ${ }^{32-34}$ A. diaperinus larvae feed on different sources of food, such as wood, paper and chicken faeces. For the US population of $A$. diaperinus, it was shown that adults and larvae of $A$. diaperinus are attracted to poultry litter odour, and that the combination of aggregation pheromone and chicken faeces is more attractive to larvae than the aggregation pheromone alone. ${ }^{18}$ Larvae might be more responsive to odour from food sources than to odour of conspecific adults, i.e. the aggregation pheromone. This hypothesis could be tested by evaluating larvae responses to conspecific aggregation pheromone. The absence of trapped larvae in our experiments might also be related to our trap design, i.e. the opening of the pitfall trap is on the top of the cap, above the poultry litter, and the external wall of the plastic traps is smooth, which makes it difficult for larvae to move along. Furthermore, during the experiments, larvae were hardly ever seen on the top of the litter, which would be required prior to trap entry.

Deployment of the alarm pheromone for $A$. diaperinus as well as the aggregation pheromone in the push-pull experiment significantly increased trap catches compared with the pull experiment. This suggests that the alarm pheromone can displace $A$. diaperinus from its hiding places and allows more insects to be captured in the aggregation pheromone-baited traps. The efficiency of the displacing effect caused by the push-pull strategy compared with the pull strategy can be correlated with the increased number of insects captured also in the control traps in the push-pull system compared with the pull system. Aggregation pheromone traps could potentially lose their efficacy under conditions with high $A$. diaperinus population levels, due to competition with the natural pheromone released by insects in the control area. However, in our study, the use of the alarm pheromone to disturb the insects from their hiding places promoted higher mobility and consequently increased the likelihood of insects being caught in traps. This illustrates the potential of semiochemical-based push-pull systems for pest management, and how the combination of two different classes of semiochemicals can enhance their ability to manage a pest. The most successful push-pull system currently in use for pest management is for cereal stemborers in Eastern 
Africa, involving the use of repellent intercrops and attractive trap plants alongside cereal crops to regulate the population of the targeted pest and their natural enemies. ${ }^{23,35-38}$ Push-pull systems have also been tested for the mountain pine beetle, Dendroctonus ponderosae Hopkins (Coleoptera: Curculionidae), showing promising results for management of this pest, ${ }_{1}^{39}$ and for the Douglas fir beetle, D. pseudotsugae Hopkins (Coleoptera: Curculionidae), where the use of anti-aggregation and aggregation pheromone reduced the pest population by $\sim 80 \%{ }^{40}$

Although benzoquinones are considered potentially toxic compounds, the quantities used in this study are equivalent to the amounts stored in the abdominal glands of $\sim 200$ A. diaperinus, and the quantity released by 10000 insects when disturbed. ${ }^{20}$ Because it is well known that $A$. diaperinus populations can reach several thousand in poultry houses, the quantity of the alarm pheromone deployed in our experiments already exists in poultry houses under natural conditions. However, because $A$. diaperinus is completely adapted to poultry houses conditions, where there is no competition for food and reproductive partners, it is possible that the lower amounts used in our experiments were sufficiently effective to cause disaggregation in the areas where alarm pheromone was released. In the long term, insect population reduction will provide a safer environment for birds and humans. More experiments are needed to show if the push-pull strategy can reduce $A$. diaperinus populations over time and maintain low insect numbers.

A. diaperinus populations are difficult to manage because their cryptic behaviour reduces contact with control agents such as insecticides. Furthermore, control agents can only be applied at times when flocks are not present, to avoid side effects. Reduction of the population level of $A$. diaperinus in commercial poultry houses could involve a long-term experiment $(6$ months to 1 year experiment) using semiochemicals combined with sanitary measures such as periodic changes of poultry litter, the use of brickwork poultry houses, and cleaning the surrounding areas of the poultry houses to restrict the movement of insects between the facilities. A pull or push-pull strategy that uses aggregation pheromones and alarm/aggregation pheromones respectively could be used, with aggregation pheromone-baited traps containing a control agent such as a biopesticide to capture, infect and kill insects. Traps combined with biological control agents could also be placed in the external areas of the poultry houses to capture migrating insects. The risk of toxic effects of the semiochemicals upon birds and humans would be minimized because the pheromone lures are enclosed in traps, there is no physical contact with the emitted chemicals, and the pheromones are released at physiologically relevant levels, i.e. levels released by the insects. An attract-and-kill strategy that combines the use of entomopathogenic fungi with attractant pheromones has been described previously for other insects, e.g. the grain borer, Prostephanus truncates (Coleoptera: Bostrichidae), the western flower thrips, Frankliniella occidentalis (Thysanoptera: Thripidae), and the banana weevil, Cosmopolites sordidus (Coleoptera: Curculionidae). ${ }^{41-45}$ We believe that this combined approach has the potential to be used for A. diaperinus management. However, fungi could be applied either as a powder or as a fat formulation in pheromone traps, with the pathogen being protected from the litter fungicide, and the insects being brought into contact with the pathogen in the pheromone traps. ${ }^{46-50}$

In conclusion, our results suggest that alarm and aggregation pheromones can be deployed under poultry house conditions to trap significant numbers of adult $A$. diaperinus. Further long-term studies are underway to determine whether pheromone deployment can be combined with suitable entomopathogenic fungi to maintain A. diaperinus populations at low levels over time, and to evaluate the potential for using these components as part of an integrated $A$. diaperinus management strategy.

\section{ACKNOWLEDGEMENTS}

We thank Carmen SS Pires and Tamin Matar for the use of their poultry houses in Brasilia DF and Nelson Bauermann and Gracian Panizzon from BRF Concórdia for the use of the poultry houses in Santa Catarina and the postgraduate zoology program of the University of Brasília (UnB) for use of their facility. This work received financial support from the Coordination of Superior Level Staff Improving (CAPES) through a grant to MJH (88881.1317661/2014-2101, the National Counsel of Technological and Scientific Development (CNPq), the Federal District Research Foundation (FAP-DF) and the Brazilian Corporation of Agricultural Research (EMBRAPA). Rothamsted Research receives grant-aided support from the Biotechnology and Biological Sciences Research Council (BBSRC) of the United Kingdom.

\section{SUPPORTING INFORMATION}

Supporting information may be found in the online version of this article.

\section{REFERENCES}

1 Axtell RC and Arends JJ, Ecology and management of arthropod pests of poultry. Annu Rev Entomol 35:101-126 (1990).

2 Dunford JC and Kaufman PE, Lesser Mealworm, Litter Beetle, Alphitobius diaperinus (Panzer) (Insecta: Coleoptera: Tenebrionidae). (2006). Available: http://edis.ifas.ufl.edu/pdffiles/IN/IN66200.pdf [4 April 2018].

3 Japp AK, Bicho CL and Silva AVF, Importância e medidas de controle para Alphitobius diaperinus em Aviários. Cienc Rural 40:1668-1673 (2010).

4 Salin C, Delettre YR, Cannavacciuolo M and Vernon P, Spatial distribution of Alphitobius diaperinus (Panzer) (Coleoptera: Tenebrionidae) in the soil of a poultry house along a breeding cycle. Eur J Soil Biol 36:107-115 (2000).

5 Lambkin TA, Kopittke RA, Rice SJ, Bartlett JS and Zalucki MP, Distributions of lesser mealworm (Coleoptera: Tenebrionidae) in litter of a compacted earth-floor broiler house in subtropical Queensland, Australia. J Econ Entomol 100:1136-1146 (2007).

6 Lambkin TA, Kopittke RA, Rice SJ, Bartlett JS and Zalucki MP, Factors affecting localized abundance and distribution of lesser mealworm in earth-floor broiler houses in subtropical Australia. J Econ Entomol 101:61-67 (2008).

7 McAllister JC, Steelman CD, Newberry LA and Skeeles JK, Isolation of infectious bursal disease virus from the lesser mealworm, Alphitobius diaperinus (Panzer). Poult Sci 74:45-49 (1995).

8 Goodwin MA and Waltman WD, Transmission of Eimeria, viruses and bacteria to chicks: darkling beetles (Alphitobius diaperinus) as vectors of pathogens. J Appl Poultry Res 5:51 -55 (1996).

9 Hazeleger WC, Bolder MN, Beumer RR and Jacobs-Reitsma WF, Darkling beetles (Alphitobius diaperinus) and their larvae as potential vectors for the transfer of Campylobacter jejuni and Salmonella enterica serovar paratyphi B variant Java between successive broiler flocks. Appl Environ Microbiol 74:6887-6891 (2008).

10 Leffer AM, Kuttel J, Martins LM, Pedroso AC, Astolfi-Ferreira CS, Ferreira F et al., Vectorial competence of larvae and adults of Alphitobius diaperinus in the transmission of Salmonella enteritidis in poultry. Vector Borne Zoonotic Dis 10:481 - 487 (2010).

11 World Health Organization, Pesticide Residues in Food - 2016: Toxicological Evaluations. Available: www.fao.org/3/a-i5693e.pdf [4 April 2018]. 
12 Lambkin TA, Rice SJ and Furlong MJ, Responses of susceptible and cyfluthrin-resistant broiler house populations of lesser mealworm (Coleoptera: Tenebrionidae) to $\lambda$-cyhalothrin. J Econ Entomol 103:2155-2163 (2010)

13 Lambkin TA and Furlong MJ, Metabolic mechanisms only partially explain resistance to pyrethroids in Australian broiler house populations of lesser mealworm (Coleoptera: Tenebrionidae). J Econ Entomol 104:629-635 (2011).

14 Chernaki-Leffer AM, Sosa-Gòmez DR and Almeida LM, Selection for entomopathogenic fungi and $\mathrm{LD}_{50}$ of Metarhizium anisopliae (Metsch.) Sorok. for the lesser mealworm Alphitobius diaperinus (Panzer) (Coleoptera: Tenebrionidae). Braz J Poultry Sci 9:187-191 (2007).

15 Pezowicz E, Mazurkiewicz A and Tumialis D, Sensitivity of imago and larvae of the lesser mealworm Alphitobius diaperinus (Panzer 1797) in a sawdust litter to selected species and strains of Steinernematidae and Heterorhabditidae under laboratory conditions. Anim Sci 52:161-166 (2013).

16 Prado GP, Stefani LM, Silva AS, Smaniotto LF, Garcia FRM and Moura $\mathrm{NF}$, Alphitobius diaperinus (Coleoptera: Tenebrionidae) susceptibility to Cunila angustifolia essential oil. J Med Entomol 50:1040-1045 (2013).

17 Bartelt RJ, Zilkowski BW, Cossé AA, Steelman CD and Singh N, Male-produced aggregation pheromone of the lesser mealworm beetle, Alphitobius diaperinus. J Chem Ecol 35:422-434 (2009).

18 Singh $\mathrm{N}$ and Johnson DT, Attractiveness of an aggregation pheromone lure and chicken droppings to adults and larvae of Alphitobius diaperinus (Coleoptera: Tenebrionidae). J Econ Entomol 105:2196-2206 (2012).

19 Cossé AA and Zilcowski BW, Behavioural responses of lesser mealworm beetles, Alphitobius diaperinus, (Coleoptera: Tenebrionidae) to pheromone components using a wind tunnel dual choice walking bioassay. J Insect behav 28:202-210 (2015).

20 Hassemer MJ, Sant'Ana J, de Oliveira MW, Borges M, Laumann RA, Caumo $\mathrm{M}$ et al., Chemical composition of Alphitobius diaperinus (Coleoptera: Tenebrionidae) abdominal glands and the influence of 1,4-benzoquinones on its behavior. J Econ Entomol 108:2107-2116 (2015).

21 Hassemer MJ, Sant'Ana J, Borges M, Withall D, Pickett JA, de Oliveira MWM et al., Revisiting the male-produced aggregation pheromone of the lesser mealworm, Alphitobius diaperinus (Coleoptera, Tenebrionidae): identification of a six-component pheromone from a Brazilian population. J Agric Food Chem 64:6809-6818 (2016).

22 Miller JR and Cowles RS, Stimulo-deterrent diversion: a concept and its possible application to onion maggot control. J Chem Ecol 16:3197-3212 (1990).

23 Cook SM, Khan ZR and Pickett JA, The use of push-pull strategies in integrated pest management. Annu Rev Entomol 52:375-400 (2007).

24 Fraser D, Towards a global perspective on farm animal welfare. Appl Anim Behav Sci 113:330-339 (2008).

25 R Development Core Team, R: A Language and Environment for Statistical Computing. R Foundation for Statistical Computing, Vienna (2011).

26 Kuenen LPS and Siegel JP, Measure your septa release ratios: pheromone release ratio variability affected by rubber septa and solvent. J Chem Ecol 41:303-310 (2015).

27 Tumlinson $\mathrm{JH}$, Hardee DD, Gueldner RC, Thompson AC, Hedin PA and Minyard JP, Sex pheromone produced by the male boll weevil: isolation, identification, and synthesis. Science 166:1010-1012 (1969).

28 Fontes EMG, Ramalho FS, Underwood E, Barroso PAV, Simon MF, Sujii ER et al., The cotton agricultural context in Brazil, in Environmental Risk Assessment of Genetically Modified Organism: Methodologies for Assessing Bt Cotton in Brazil, ed. by Hilbeck A, Andow D and EMG F. CABI, Wallingford, p. 400 (2006).

29 Jaffé K, Sánchez P, Cerda H, Hernández JV, Jaffé R, Urdaneta N et al., Chemical ecology of the palm weevil Rhynchophorus palmarum (L.) (Coleoptera: Curculionidae): attraction to host plants and to a male-produced aggregation pheromone. J Chem Ecol 19:1703-1720 (1993).

30 Athanassiou CG, Kavallieratos NG and Trematerra P, Responses of Sitophilus oryzae (Coleoptera: Curculionidae) and Tribolium confusum (Coleoptera: Tenebrionidae) to traps baited with pheromones and food volatiles. Eur J Entomol 103:371-378 (2006).
31 Fedina TY and Lewis SM, Effect of Tribolium castaneum (Coleoptera: Tenebrionidae) nutritional environment, sex, and mating status on response to commercial pheromone traps. J Econ Entomol 100:1924-1927 (2007).

32 Mondal KAMSH and Port GR, Response of Tribolium castaneum larvae to synthetic aggregation pheromone. Entomol Exp Appl 36:43-46 (1984).

33 Hammock JA, Vinyard B and Dickens JC, Response to host plant odors and aggregation pheromone by larvae of the Colorado potato beetle on a servosphere. Arth-Plant Int 1:27-35 (2007).

34 Duthie B, Gries G, Gries R, Krupke C and Derksen S, Does pheromone based aggregation of codling moth larvae help procure future mates? J Chem Ecol 29:425-436 (2003).

35 Khan ZR, Ampong-Nyarko K, Chiliswa P, Hassanali A, Kimani S, Lwande $W$ et al., Intercropping increases parasitism of pests. Nature 388:631-632 (1997a).

36 Khan ZR, Chiliswa P, Ampong-Nyarko K, Smart LE, Polaszek A, Wandera J et al., Utilisation of wild gramineous plants for management of cereal stemborers in Africa. Insect Sci Appl 17:143-150 (1997b)

37 Khan ZR, Pickett JA, van den Berg J, Wadhams LJ and Woodcock $\mathrm{CM}$, Exploiting chemical ecology and species diversity: stem borer and striga control for maize and sorghum in Africa. Pest Manag Sci 56:957-962 (2000).

38 Khan ZR, Midega CA, Bruce TJ, Hooper AM and Pickett JA, Exploiting phytochemicals for developing a push-pull crop protection strategy for cereal farmers in Africa. J Exp Bot 61:4185-4196 (2010).

39 Lindgren BS and Borden JH, Displacement and aggregation of mountain pine beetles, Dendroctonus ponderosae (Coleoptera: Scolytidae), in response to their antiaggregation and aggregation pheromones. Can J For Res 23:286-290 (1993).

40 Ross DW and Daterman GE, Reduction of Douglas-fir beetle infestation of high risk stands by antiaggregation and aggregation pheromones. Can J For Res 24:2184-2190 (1994).

41 Smith SM, Moore D, Karanja LW and Chandi EA, Formulation of vegetable fat pellets with pheromone and Beauveria bassiana to control the larger grain borer, Prostephanus truncatus (horn). Pestic Sci 55:711-718 (1999).

42 Niassy S, Maniania NK, Subramanian S, Gitonga LM and Ekesi S, Performance of a semiochemical-baited autoinoculation device treated with Metarhizium anisopliae for control of Frankliniella occidentalis on French bean in field cages. Entomol Exp Appl 142:97-103 (2012).

43 Tinzaara W, Gold CS, Nankinga C, Dicke M, van Huis A, Ragama PE et al., Integration of pheromones and entomopathogenic fungus for the management of the banana weevil. J Agric Sci 9:621-629 (2004).

44 Tinzaara W, Gold CS, Dicke M, van Huis A, Nankinga CM, Kagezi GH et al., The use of aggregation pheromone to enhance dissemination of Beauveria bassiana for the control of the banana weevil in Uganda. Biocontrol Sci Technol 17:111-124 (2007).

45 Lopes RB, Laumann RA, Moore D, Oliveira MWM and Faria M, Combination of the fungus Beauveria bassiana and pheromone in attract-and-kill satrategy against the banana weevil, Cosmopolites sordidus. Entomol Exp Appl 151:75-85 (2014).

46 Alves LFA, Gassen MH, Pinto FGS, Neves PMOJ and Alves SB, Ocorrência natural de Beauveria bassiana (Bals.) Vuill. (Moniliales: Moniliaceae) sobre o cascudinho, Alphitobius diaperinus (Panzer) (Coleoptera: Tenebrionidae), em aviário comercial de Cascavel, PR. Neotrop Entomol 34:507-510 (2005).

47 Rohde C, Alves LFA, Neves PMOJ, Alves SB, Silva ERL and Almeida JEM, Seleção de isolados de Beauveria bassiana (Bals.) Vuill. e Metarhizium anisopliae (Metsch.) Sorok. contra o cascudinho Alphitobius diaperinus (Panzer) (Coleoptera: Tenebrionidae). Neotrop Entomol 35:231-240 (2006).

48 Santoro PH, Neves PMOJ, Alexandre TM, Sartori D, Alves LFA and Fungaro M, Selection of Beauveria bassiana isolates to control Alphitobius diaperinus. J Invertebr Pathol 97:83-90 (2008).

49 Rezende SRF, Curvello FA, Fraga ME, Reis CS, Castilho AMC and Agostinho TSP, Control of the Alphitoibus diaperinus (panzer) (Coleoptera: Tenebrionidae) with entomopathogenic fungi. Braz J Poultry Sci 11:121-127 (2009).

50 Alves LFA, Oliveira DGP, Lambkin T, Bonini AK, Alves V, Pinto FGS et al., Beauveria bassiana applied to broiler chicken houses as biocontrol of Alphitobius diaperinus panzer (Coleoptera: Tenebrionidae), an avian pathogens vector. Rev Bras Cienc Avic 17:459-466 (2015). 